\section{Guidance for U.S. Laboratory Testing for Zika Virus Infection: Implications for Health Care Providers}

CDC has released updated guidance online for U.S. laboratory testing for Zika virus infection. The guidance is available at https://www.cdc.gov/zika/laboratories/lab-guidance.html. Frequently asked questions are addressed at https://www.cdc. gov/zika/laboratories/lab-guidance-faq.html. This guidance updates recommendations for testing of specimens by U.S. laboratories for possible Zika virus infection. Major updates to the guidance with clinical implications for health care providers include the following:

- In addition to specimens listed in CDC's clinical guidance (1-3), whole blood can now be tested for Zika virus RNA in accordance with the Emergency Use Authorization (EUA) for Zika virus nucleic acid testing (NAT)* for a) symptomatic persons tested up to 14 days after onset of symptoms, b) asymptomatic pregnant women tested within 14 days of last possible Zika virus exposure, and c) infants tested for congenital Zika virus infection.

- The use of plaque reduction neutralization testing (PRNT) for confirmation of Zika virus infection, including in pregnant women and infants, is currently not routinely recommended in Puerto Rico.

\footnotetext{
* Whole blood is not an approved specimen for all NAT EUA assays; health care providers should confirm with their testing laboratory that it can accept whole blood specimens prior to collecting and submitting this sample type.
}

- PRNT can be used to test for congenital Zika virus infection in children aged $\geq 18$ months; maternally derived antibodies in the infant are expected to have waned, and therefore PRNT results will reflect infant-derived antibodies. Local health departments should determine when to implement testing of infants aged $\geq 18$ months based on local context, including the regional circulation of similar flaviviruses, laboratory capacity, and other epidemiologic circumstances.

The updated guidance for laboratories has clinical implications for health care providers caring for pregnant women with possible Zika virus exposure, infants with possible congenital Zika virus infection, and nonpregnant persons with suspected Zika virus disease.

\section{References}

1. CDC. Clinical guidance for healthcare providers caring for pregnant women. Atlanta, GA: US Department of Health and Human Services, CDC; 2016. http://www.cdc.gov/zika/hc-providers/pregnant-woman.html

2. CDC. Clinical guidance for healthcare providers caring for infants $\&$ children. Atlanta, GA: US Department of Health and Human Services, CDC; 2016. http://www.cdc.gov/zika/hc-providers/infants-children.html

3. CDC. Clinical guidance for healthcare providers for prevention of sexual transmission of Zika virus. Atlanta, GA: US Department of Health and Human Services, CDC; 2016. http://www.cdc.gov/zika/hc-providers/ clinical-guidance/sexualtransmission.html 


\section{National Family History Day — November 24, 2016}

In 2004, the U.S. Surgeon General declared that Thanksgiving would be National Family History Day, a day designed to encourage American families to learn about and create a written record of their family health history. Family history can identify those persons with a higher-than-average risk for many common diseases, such as heart disease, cancer, and type 2 diabetes. Having at least one first-degree relative with a disease can increase a person's risk twofold or more (1). Family history is also a determinant of less common diseases like sickle cell disease and cystic fibrosis (1). Persons who might be at increased risk because of family history might benefit from screening or other interventions to prevent disease or detect it earlier.

An estimated $20 \%$ of women with family histories of breast and ovarian cancer might have cancer-causing mutations in $B R C A$ genes (2). Discussing family history of cancer with patients can help providers identify persons at higher-thanaverage risk, foster discussions about genetic counseling and testing, and help them make informed decisions about risk reduction. Public health programs at the federal and state levels are working to increase collection and assessment of family history and identify persons at high risk and their families.
This Thanksgiving, CDC encourages everyone to learn about their family histories of cancer and other conditions. Several resources are available to help facilitate these conversations, including the U.S. Surgeon General's Family History Initiative's Before You Start (http://www.hhs.gov/sites/default/ files/familyhistory/start/startenglish.pdf) and My Family Health Portrait Tool (https://familyhistory.hhs.gov/FHH/ $\mathrm{html} /$ index.html), CDC's information on family history (http://www.cdc.gov/genomics/famhistory/index.htm), and the Know:BRCA Family Cancer History worksheet (https:// www.knowbrca.org/Learn/gathering-family-history).

\section{References}

1. Valdez R, Yoon PW, Qureshi N, Green RF, Khoury MJ. Family history in public health practice: a genomic tool for disease prevention and health promotion. Annu Rev Public Health 2010;31:69-87. http://dx.doi. org/10.1146/annurev.publhealth.012809.103621

2. Nelson HD, Fu R, Goddard K, et al. Risk assessment, genetic counseling, and genetic testing for BRCA-related cancer: systematic review to update the U.S. Preventive Services Task Force Recommendation. Evidence Synthesis No. 101. Agency for Healthcare Research and Quality publication no. 12-05164-EF-1. Rockville, MD: Agency for Healthcare Research and Quality; 2013. 